\title{
"Atypical" Phenotypes of Neuronal Ceroid Lipofuscinosis: The Argentine Experience in the Genomic Era
}

Journal of Inborn Errors of Metabolism \& Screening 2021, Volume 9: e20210009 DOI: https://doi.org/10.1590/2326-4594JIEMS-2021-0009

\author{
Favio Pesaola ${ }^{1,2}$ (D), Guillermo Guelbert ${ }^{1,3}$, Ana Clara Venier ${ }^{1,2}$ (D), \\ Inés Adriana Cismondi ${ }^{1,4}$, Adriana Becerra ${ }^{1,3}$, Juan Carlos G. Vazquez ${ }^{6}$, \\ Elmer Fernandez ${ }^{6}$, Ana Lucia De Paul| ${ }^{2,7}$, Norberto Guelbert ${ }^{1,5}$ and Inés Noher ${ }^{1}$ (D)
}

\begin{abstract}
Neuronal Ceroid Lipofuscinosis (NCL) refers to a group of inherited lysosomal storage disorders characterized by the intracellular accumulation of ceroid-lipofuscin compounds and neurodegeneration. Fourteen genes are currently recognized with diseasecausing DNA variants: PPT1/CLN1, TPP1/CLN2, CLN3, DNAJC5/CLN4, CLN5, CLN6, MFSD8/CLN7, CLN8, CTSD/CN10, GRN/CLN11, ATP13A2/CLN12, CTSF/CLN13, KCTD7/CLN14, TBCK/CLN15. In the frame of the Cordoba cohort, we studied N=51 cases. The aim of this paper is the observational and retrospective analysis of the "atypical" phenotypes. PCR-Sanger sequencing and/or massive exome sequencing were used as a screening methodology. One CLN1 subject showed an atypical prolonged $(P)$ phenotype with null PPT1 activity and a heterozygous compound genotype: E5 c.451C>T, p.Arg151*/g.6302T>G (I3 c.363-3T>G). Other 11 CLN2 individuals (except one girl) showed TPP1 activity decreased to around 10\% of the minimum value of the reference interval in leukocytes and saliva. The DNA variants E7 c.827A>T, p.Asp276Val and 17 c.887-10A >G were the most prevalent. One CLN8 individual showed an atypical congenital phenotype with a heterozygous combination of DNA variants: E2 c.1A>G, p.?/E3 c.792C>G, p.Asn264Lys. Massive sequencing was installed as a screening methodology for the precision diagnosis of atypical CLN1, CLN2, and CLN8 phenotypes. A genetic/phenotypic local registry is under construction.
\end{abstract}

\section{Keywords:}

Neuronal Ceroid Lipofuscinosis, Genomics, CLN1, CLN2, CLN8, Atypical Phenotypes.

\section{Introduction}

Neuronal Ceroid Lipofuscinosis (NCL) refers to a group of lysosomal storage diseases characterized by the intracellular accumulation of lipofuscin-like compounds.[1] Even though these accumulations can be observed in all cells, neurons are the most affected, resulting in neuronal death and neurodegenerative syndrome. [2] The onset of symptoms can occur at any age. There is no cure for these disorders, except a treatment for one of the forms (CLN2 disease) approved in 2017 by the US Food and Drug Administration (https://www.ninds.nih.gov/disorders/patientcaregiver-education/fact-sheets/batten-disease-fact-sheet).[3] In most NCL forms, the affected individuals die prematurely around the second or third decade of life. Variations in the life span occur in the different forms.[4]

\footnotetext{
${ }^{1}$ Universidad Nacional de Córdoba, Hospital de Niños de la Provincia de Córdoba, Programa de Investigación Traslacional de Lipofuscinosis Ceroideas Neuronales, Ferroviarios, 1250, 5000, Córdoba, Argentina.

${ }^{2}$ Instituto de Investigación en Ciencias de la Salud, Consejo Nacional de Investigaciones Científicas y Técnica, Bv. de la Reforma y Enfermera Gordillo, Ciudad Universitaria, 5000, Córdoba, Argentina.

${ }^{3}$ Hospital de Niños de la Provincia de Córdoba, Sección de Enfermedades Metabólicas Hereditarias, Ferroviarios, 1250, 5000, Córdoba, Argentina.

${ }^{4}$ Universidad Nacional de Córdoba, Facultad de Odontología, Haya de la Torre s/n, 5000, Córdoba, Argentina.

${ }^{5}$ Clínica Universitaria Reina Fabiola, Oncativo, 1248, 5004, Córdoba, Argentina.

${ }^{6}$ Universidad Católica de Córdoba, Consejo Nacional de Investigaciones Científicas y Técnicas, Centro de Investigación y Desarrollo en Inmunología y Enfermedades Infecciosas, Campus Universitario UCC, Av. Armada Argentina, 3555, 5017, Córdoba, Argentina.

${ }^{7}$ Universidad Nacional de Córdoba, Facultad de Ciencias Médicas, Centro de Microscopía Electrónica, Bv. de la Reforma y Enfermera Gordillo, Ciudad Universitaria, 5016, Córdoba, Argentina.
}

Received January 31, 2021, and in revised form March 23, 2021. Accepted for publication March 29, 2021.

Corresponding Author:

Ines Noher, Email: ines.de@unc.edu.ar 
Different phenotypes are known as congenital (CNCL), infantile (INCL), late infantile (LINCL), juvenile (JNCL), and adult (ANCL) according to the onset age. Fourteen genes are currently recognized with DNA variants of pathogenic significance: $P P T 1 /$ CLN1, TPP1/CLN2, CLN3, DNAJC5/CLN4, CLN5, CLN6, MFSD8/ CLN7, CLN8, CTSD/CN10, GRN/CLN11, ATP13A2/CLN12, CTSF/CLN13, KCTD7/CLN14, TBCK/CLN15.[5,6] Nevertheless, the name Batten disease has been used in the US to unify the spectrum of clinical and pathological conditions.[7] The term "atypical" was coined to define "uncommon" phenotypes within a certain genotype. For instance, the "classical" CLN2 disease is characterized by some predominant genetic variants. [8,9] Its "atypical" (protracted or prolonged) phenotype, including SCAR7 disease (OMIM \#609270), differs from the "classical" course, mostly due to different DNA variants in the same gene. Other NCL diseases are named "variant" (followed by the name of the gene) when a different genetic background underlies similar phenotypes. For example, variant Late Infantile (vLI) CLN8.[4,5] In this article, we use the nomenclature proposed by an international consensus of experts https://www.ucl.ac.uk/ $\mathrm{ncl} /$ newnomenclature.shtml[10], and the nomenclature and classification of the McKusick Catalog of genetic diseases (https:// www.omim.org/).[11] The Williams \& Mole nomenclature[10] is an axial diagnostic classification system similar to the one used for epilepsies and mental health disorders in children (ICD10). Williams \& Mole[10] take into consideration the following analytical axes: 1) affected gene; 2) DNA variant definition; 3) biochemical phenotype (for example, enzyme deficiencies of PPT1, TPP1, and CTSD); 4) clinical phenotype (onset age); 5) fine structural and light microscopy features; 6) functionality (rating scales); 7) other remarks, e. g. swallowing. Axes 5,6, and
7 may not be necessary or useful in the majority of cases. The axial nomenclature system is condensed in a graphical heptagon useful to guide the recognition of individuals affected by an NCL disease in a clinical context (Figure 1).

The proteomic etiology has been determined for all NCL pathologies; however, the function of several of the involved proteins, as well as their relationship to lysosomal storage, remain poorly understood. Some of the NCL-associated proteins are found in lysosomes as soluble enzymes (PPT1, TPP1, CLN5, CTSD, CTSF, and GRN) or as integral membrane protein (CLN3, MFSD8, and ATP13A2); others are located in the endoplasmic reticulum (CLN6 and CLN8), cytosol (DNAJC5, KCTD7, and TBCK) or plasma membrane (CLN3).[5] Figure 2 shows a diagram of the location and structure of the proteins associated with NCL. The activity of enzymes PPT1, TPP1, and CTSD are measured for diagnostic purposes of the respective diseases.[12-15]

The worldwide incidence of NCLs was estimated between 1-30 affected individuals per 100,000 live births, depending on the region[16]; as a whole, they are the most frequent neurodegenerative diseases of childhood.[1] The NCL data resource, https://www.ucl.ac.uk/ncl-disease/, registered around 1300 individuals with around 500 damaging DNA variants. In recent years, a series of publications added information on Latin American NCL cases.[8,15,17-22] The NCL screening program of Cordoba (located in the Middle of Argentina) collected since $2003 \mathrm{~N}=51$ cases with a precise diagnosis, named altogether the Cordoba cohort, the biggest one studied in LA. Probably, the NCL diseases remain underdiagnosed in most of the LA countries. Massive sequencing methods (NGS) have reduced the time towards the precision diagnosis as early as

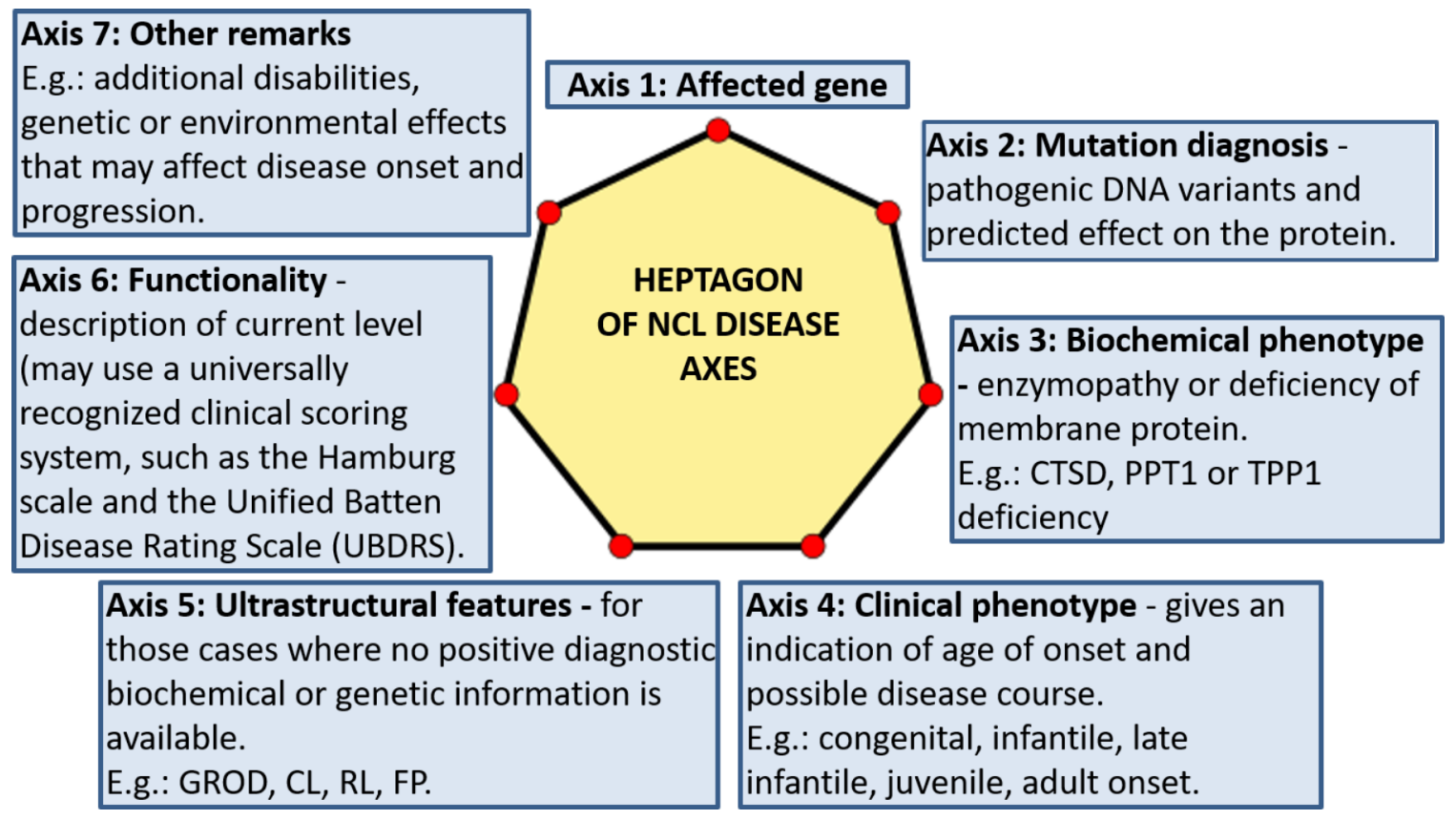

Figure 1. Diagram of the nomenclature heptagon, useful as a guide for the diagnosis of NCL diseases. Axes 1 and 4 abbreviate the study of the diseases. GROD, granular osmiophilic deposits; CL, curvilinear bodies, RL, rectilinear bodies; FP, fingerprint profiles. 


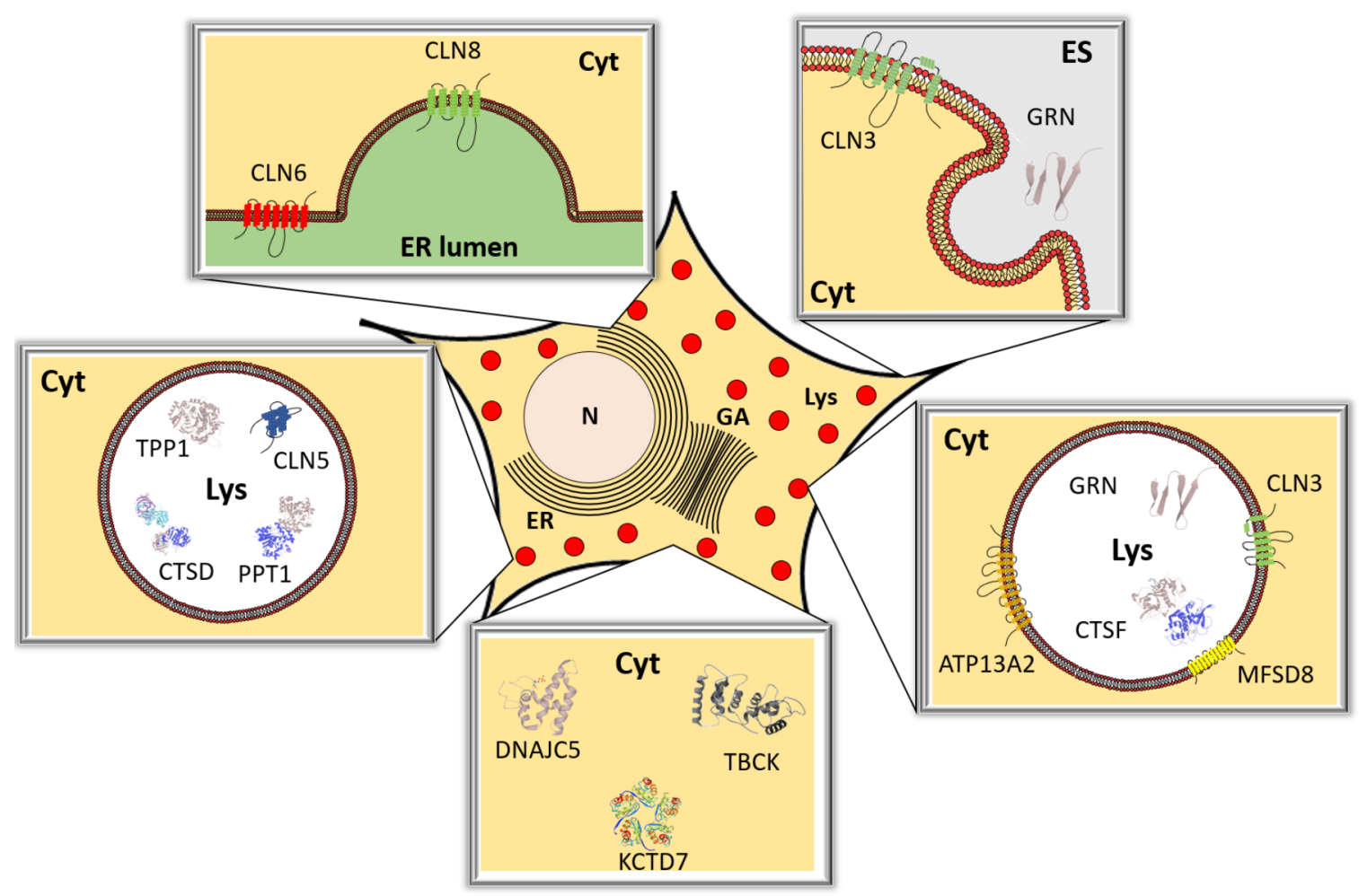

Figure 2. Diagram of the cellular localization and structure of the NCL-associated proteins. The soluble proteins PPT1 (CLN1), TPP1 (CLN2), CLN5, CTSD (CLN10), GRN (CLN11), CTSF (CLN13), KCTD7 (CLN14), and TBCK (CLN15) are represented according to the 3D structure obtained from the UniProt database (https://www.uniprot.org/). The transmembrane proteins CLN3, DNAJC5 (CLN4), CLN6, MFSD8 (CLN7), CLN8, and ATP13A2 (CLN12) are outlined according to the approximate topology obtained from the UniProt database. Cyt, cytosol; ER, endoplasmic reticulum; ES, extracellular space; GA, Golgi apparatus; Lys, lysosome; N, nucleus.

possible in the evolution of signs and symptoms[23], and gained greater value since ERT for CLN2 disease introduced changes in the CLN2 pathology progression.[3,20,24-26] The general purpose of the present article is to report an observational and retrospective study on "atypical" phenotypes of CLN1, CLN2, and CLN8 diseases in the Cordoba cohort, which show clinical and genomic heterogeneity. A specific aim is to offer an analytical frame of the phenotypic (clinical), proteomic, and genomic characterization for contributing to the study of these "atypical" NCL phenotypes in LA.

\section{Subjects and Methods}

\section{Subjects}

Clinical and experimental protocols were carried out in compliance with the 2005 UNESCO Universal Declaration on Bioethics and Human Rights https://en.unesco.org/themes/ ethics-science-and-technology/bioethics-and-human-rights. The parents and other subjects of the Cordoba cohort were duly informed about the protocols and signed an informed consent formulary approved by the health ethics committee of the public hospital's system (Comité Interinstitucional de Ética de la Investigación en Salud [CIEIS-Polo Hospitalario]). Furthermore, the parents signed an informed consent allowing the genomic study of their child and themselves for research purposes.

The inclusion criteria were to have a precision diagnosis of an NCL with an "atypical" phenotype at any age. The subjects included in the present observational study were $n=13$ out of $\mathrm{N}=51$ subjects in the Cordoba Cohort with a precise diagnosis: $\mathrm{n}=1$ PPT1 deficiency (atypical CLN1 disease, OMIM \#256730), $\mathrm{n}=11$ TPP1 deficiency (atypical CLN2 disease, OMIM \#204500; SCAR7 disease, OMIM \#609270), n=1 CLN8 (atypical congenital CLN8 disease).

The exclusion criteria were:

1. Individuals with the most frequent LINCL or "classical" CLN2 phenotype either with the most common DNA variants c. $622 \mathrm{C}>\mathrm{T}$ and c.509-1G $>\mathrm{C}$ in homozygous or heterozygous combinations [9] or with other less frequent DNA variants described and published of the Cordoba cohort in individuals with the "classical" phenotypes.[8,27] 
2. Affected individuals with homozygous or heterozygous DNA variants in other NCL genes (CLN3, CLN5, CLN6, CLN7).

\section{Methods}

1. Study strategy (Figure 3): the clinical suspicion was emitted at any age based on the clinical signs and symptoms, studied through a set of clinical analysis, such as brain imaging (MRI), neurophysiology studies (EEG, OF, ERG, VEP, and others); transmission electronic microscopy (TEM), and light microscopy of a blood smear (LM), enzymology (PPT1 and TPP1 activity measurement in leukocyte pellet, saliva, and dried blood spots [DBS]), and genomics according to our published algorithm, and to symptomatology.[8,27]

2. Transmission Electronic Microscopy: tissues of the suspected individuals were studied through TEM to assess ceroid lipofuscin-like bodies and their morphological features. This step was replaced for the genomic screening of pathological DNA variants approximately 4 years ago. TEM was still used when no pathological DNA variants could be assessed to exclude an NCL pathology and for research purposes. The fixation, inclusion, and staining methods used in the laboratory were published elsewhere.[24,28,29]

3. Enzymology: The suspected subjects were asked for samples of DBS, peripheral blood, and saliva from the child and the parents to perform systematically enzyme activity assays of palmitoyl protein thioesterase 1 (PPT1; E.C. 3.1.2.22) and tripeptidyl peptidase 1 (TPP1; E.C. 3.4.14.9). The protocols were previously published.[8,15,22,27,28]

4. Genomics: DNA was screened through massive exome sequencing. A specific NCL panel, as well as panels for other neurodegenerative disorders (epilepsy, ataxia), were constructed and systematically analyzed. The degree of pathogenicity of new variants was experimentally (absence of the suspected variant in 200 alleles of the same population), and/or bioinformatically confirmed. Before NGS technology became accessible, DNA samples of the suspected individuals were screened out in one to several genes by PCR-Sanger methodology. Genomic DNA was isolated from peripheral blood from the suspected individual and their parents (trio methodology) by using a Wizard ${ }^{\circledR}$ Genomic DNA Purification kit (Promega, Madison, USA) following the manufacturer's protocol, and checked by agarose gel electrophoresis. Whole exome sequencing was performed by Macrogen, Inc. (Seoul, South Korea) ensuring a $100 \mathrm{X}$ covering and at least $20 \mathrm{X}$ depth. To filter and analyze the annotated variants obtained from sequencing, variant call format (vcf) files were uploaded to the MoDAPy platform (Multi-Omics Data Analysis in Python, developed by the bioinformatic division of the Catholic University of Cordoba, Argentina, https://pypi.org/project/MODApy/),

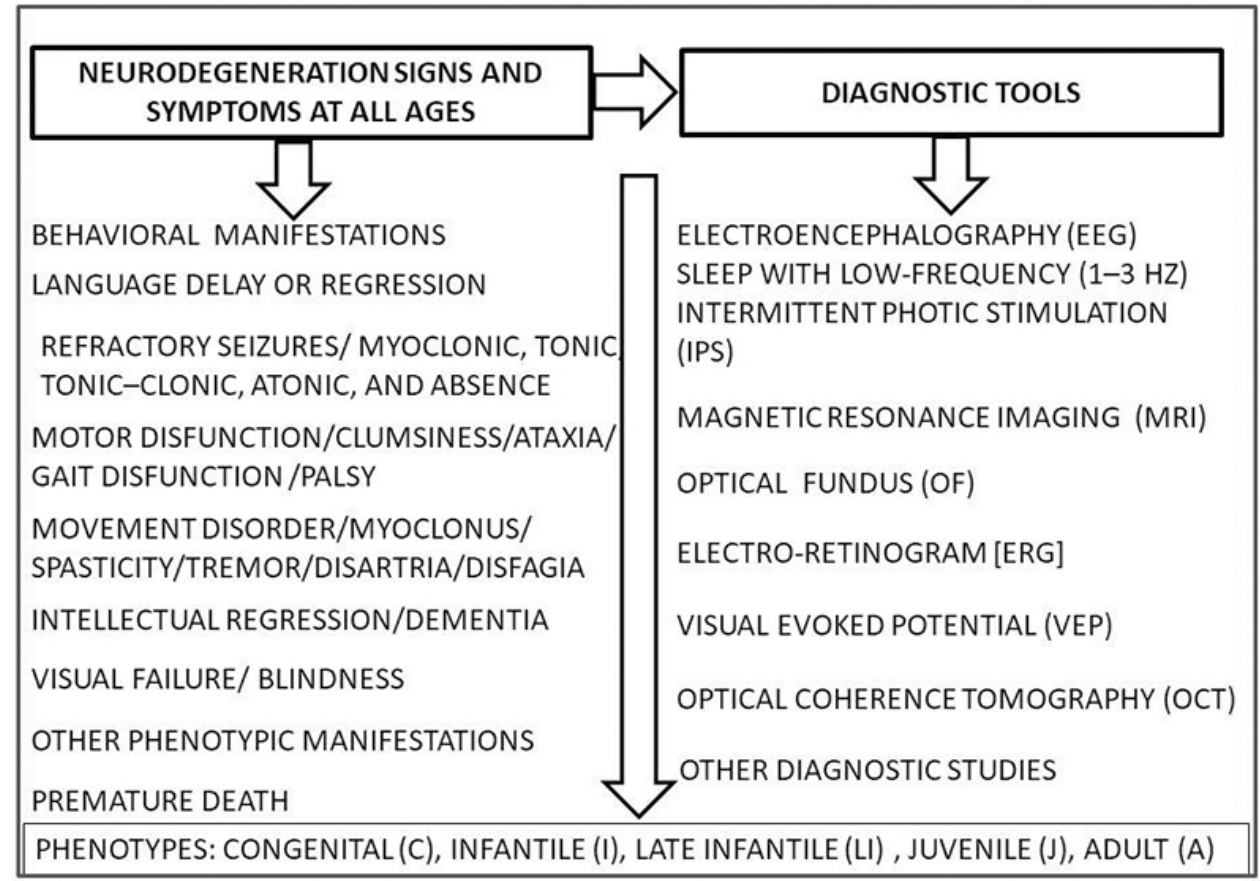

Figure 3. Study of the clinical phenotypes. Phenotypic signs and symptoms observed are listed on the left. The studies carried out to diagnose and follow-up the evolution of disease are listed on the right. Sufficient phenotypic features to consider an NCL disease were behavioral and language manifestations and other 1-2 progressive neurological symptoms listed on the left side. The clinical studies were accompanied by an enzymological evaluation of PPT1 and TPP1 activities in blood, saliva, and DBS, and mostly by TEM evaluation of the morphology of ceroid lipofuscin-like bodies in a skin biopsy. The precise genomic definition was through PCR-Sanger or NGS using a specific genetic panel or whole-exome sequencing (https://www.ucl.ac.uk/ncl-disease/).[5,10] 
and/or the B platform (Bitgenia, Buenos Aires, Argentina; https://apps2.bitgenia.com/). DNA variants were classified following the considerations of the American College of Medical Genetics and Genomics (ACMG).[30] All variants suspected to be "benign" or "likely benign" or those with high prevalence in the population were excluded as clinically relevant, and those classified as "likely pathogenic", "pathogenic" or of "uncertain significance" were evaluated by predictive software, such as Mutation Taster http:// www.mutationtaster.org/ and RESCUE-ESE http://genes. mit.edu/burgelab/rescue-ese/, by frequency on gnom AD https://gnomad.broadinstitute.org/ and 1000G databases https://www.internationalgenome.org/, and on bibliography and public databases, such as ClinVar https://www.ncbi. nlm.nih.gov/clinvar/, dbSNP https://www.ncbi.nlm.nih. gov/snp/, GeneCards https://www.genecards.org/, and NCL Resource https://www.ucl.ac.uk/ncl-disease/. Those DNA variants with high pathogenic significance were validated by PCR-Sanger sequencing in a new sample as described elsewhere. $[8,15,22,24,27,28]$ DNA variants were encoded according to the following Genbank transcript sequences: NM_000310 for the PPT1/CLN1 gene, NM_000391 for the
TPP1/CLN2 gene, and NM_018941 for the CLN8 gene. The CADD scores (a quantitative measure of the deleteriousness of a certain DNA variant) $[31,32]$ were calculated from the website https://cadd.gs.washington.edu/snv.

\section{Results and Discussion}

CLN2 disease is the most abundant NCL type in LA (64.5\%), followed by CLN3 (13.7\%). Interestingly, Argentina and Brazil bring together more than half of the reviewed patients, reflecting the support of these countries to the diagnosis and study of NCL patients. The Cordoba cohort has 51 individuals with a precise diagnosis of NCL. Out of these, 22 individuals with CLN2 disease course with the "classical" phenotype, and 11 with the "atypical" or prolonged (P) CLN2 phenotype. Furthermore, $1 / 51$ had a variant Juvenile CLN1 disease phenotype, and $1 / 51$ a variant congenital CLN8 disease phenotype (Figure 4). $[8,17,18,22,27,28,33-54]$ These variant phenotypes and their genotypes are described in the present study. Another 16/51 individuals showed other genotypes (CLN3, CLN5, CLN6, and $C L N 7$ genes) and remain out of the scope of this paper.
A) Number of cases per country.

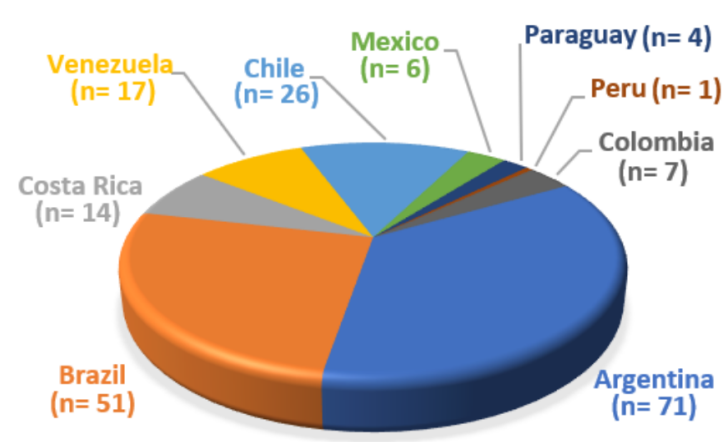

B) Number of cases per NCL genetic variant in LA.

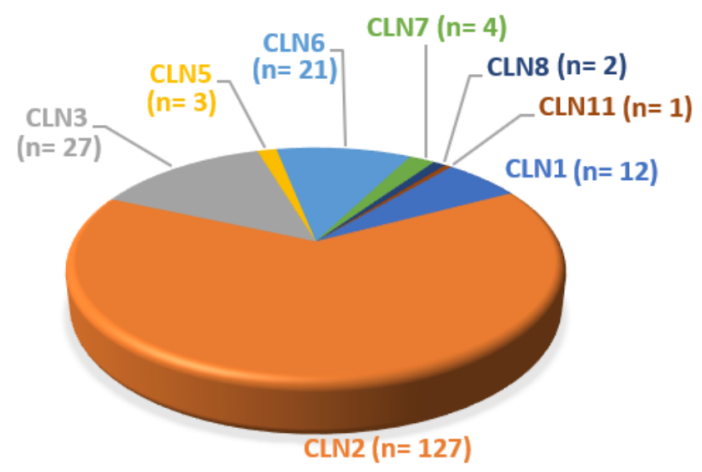

C) Number of cases per NCL genetic variant in the Cordoba cohort.

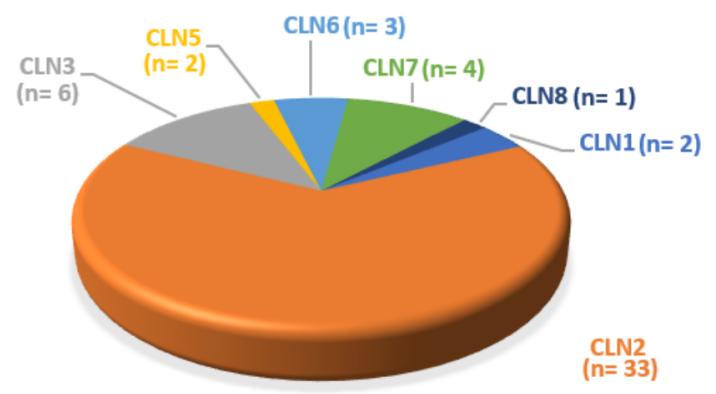

Figure 4. Distribution of the Latin American patients. Pie charts depicting the number of published patients from LA, classified A) per country and B) per NCL genetic variant. C) Pie chart representing the distribution per NCL genetic variant of the number of cases in the Cordoba cohort. Numbers should be taken as estimations, due to possible duplicated cases. It is noteworthy that Argentina and Brazil bring together more than half of the patients published in LA, as well as the CLN2 disease is the most clinically studied and described in the region. 


\section{Atypical CLN1 Disease/ PPT1 deficiency (OMIM \#256730; *600722)}

CLN1 disease (a.k.a. Santavuori-Haltia disease) is the "classical" infantile NCL phenotype[55], although it can also present as variant late infantile, juvenile or adult phenotypes. The disease is caused by pathological variants that affect the PPT1/CLN1 gene, located in chromosome $1 \mathrm{p} 32$, and hence its protein coded, PPT1, a soluble lysosomal enzyme able to remove thioesterlinked palmitate from modified cysteine residues in proteins.[56] Its deficiency leads to the accumulation of undegraded S-acylated substrates into lysosomes, typically observed as granular osmiophilic deposits (GROD) at TEM.[1]

Symptoms in "classical" INCL-CLN1 disease usually begin around 1.5 years old, including visual failure and blindness, movement impairment (ataxia, hypotonia, seizures, myoclonic jerks), and mental retardation, which course rapidly leading to an ultimate early death at the beginning of the second decade of life.[55] However, numerous cases with residual PPT1 activity have been described showing an atypical later-onset phenotype, either late infantile, juvenile, or adult.[57-61]

One Brazilian boy with German/Brazilian ancestry showed hyperactivity at 4 years old. Subsequently, he developed visual failure, tremor (6y), speech difficulties, tonic-clonic seizures (8y), ataxia, diadochokinesis, and foot clonus (9y). An MRI performed at $9 y$ revealed cerebral and cerebellar atrophy. At the same age, a skin biopsy under TEM revealed GROD profiles of lipofuscin-like accumulation, pointing to an NCL disorder. PPT1 enzyme activity on leukocytes showed null activity (10y). The DNA variants of pathogenic significance, E5 c.451C $>\mathrm{T}$, p.Arg $151^{\star}$ and g.6302T $>$ G (I3 c.363-3T >G) were found by PCRSanger sequencing in compound heterozygosity.[8] The disease progressed with loss of speech (11y), cortical myoclonus (10y), static spasticity, wheelchair-bound (14y), and total prostration (18y). He is living and bedridden at 26y.

This individual with an INCL-PPT1 P phenotype showed null enzyme activity, that oriented the genomic screening to the PPT1/CLN1 gene. Two pathogenic significant DNA variants were found, one missense and one in the splice site. The boy was diagnosed when he was 9 years old, 5 years after the first symptoms. The prolonged phenotype does not correlate with residual PPT1 activity in the leukocyte pellet, suggesting the participation of another "protective" factor that leads to a milder phenotype. Table 1 summarizes the clinically relevant data, enzyme activity and DNA variants.

Table 1. Summary of Natural History data of one individual of the Cordoba Cohort with prolonged CLN1 disease.

\begin{tabular}{|c|c|}
\hline CLN1 & Male, 26y \\
\hline Age at onset & $4 y$ \\
\hline \multicolumn{2}{|l|}{ Presenting symptoms: } \\
\hline Behavioral changes, hyperactivity & $4 y$ \\
\hline Visual failure/blind & $6 y / 9 y$ \\
\hline Seizures & $8 y$ \\
\hline Speech difficulty & $8 y$ \\
\hline Ataxia & $9 y$ \\
\hline Cerebellar-cerebral atrophy & $9 y$ \\
\hline Seizures age at onset/type & $8 y /$ tonic seizures \\
\hline \multirow[t]{5}{*}{ Movement disorders (age at onset/type) } & $6 y /$ intentional tremor \\
\hline & 9y/ adiadochokinesis \\
\hline & $9 y /$ foot clonus \\
\hline & $10 y /$ cortical myoclonus \\
\hline & $14 y /$ static spasticity \\
\hline Speech loose age & $11 y$ \\
\hline Wheelchair-bound age & $14 y$ \\
\hline Total prostration age & $18 y$ \\
\hline Electronic Microscopy age/type of dense bodies & 9y/ GROD in skin \\
\hline PPT1 deficiency/age at testing & Leukocytes: $0 \mathrm{nmol} / \mathrm{h} / \mathrm{mg}$ prot (RI:14-71), 10y \\
\hline \multirow[t]{2}{*}{ Genotype } & E5 c.451C>T, p.Arg151* (CADD score= 44) \\
\hline & I3 c.363-3T>G (CADD score= 20.4) \\
\hline Time to precision diagnosis & $5 y$ \\
\hline
\end{tabular}




\section{Atypical CLN2 Disease /TPP1 deficiency (OMIM \#204500; *607998)}

CLN2 disease is caused by mutations in the TPP1/CLN2 gene, which encodes the lysosomal enzyme TPP1.[62] The "classical" late infantile (LINCL) CLN2 disease is also known as JanskyBielschowsky disease (OMIM \#204500), and an atypical prolonged phenotype is also known as the Spinocerebellar Ataxia, Autosomal Recessive 7 (SCAR7, OMIM \#609270). The "classical" LINCL phenotype shows onset of symptoms between 2 and 4 years, including seizures, progressive psychomotor impairment, and visual failure.[4] Typically, patients show null TPP1 activity in DBS, leukocytes and saliva. $[8,28]$

In the Cordoba cohort, 33 out of 51 NCL affected individuals (64.7\%) were affected by CLN2 disease (Figure 4). Eleven/33 showed a prolonged course of the disease, and the remaining $22 / 33$ had the "classical" phenotype. Some of all the 7 axes shown in Figure 1 were recorded in the clinical histories. Available data of axial study of the CLN2 P phenotype individuals are shown in Table 2, and can be summarized as follows:

1. Affected gene: TPP1/CLN2 (location Chr. 11p15.4, 13 exons).

2. DNA variants with pathological significance at the TPP1/CLN2 gene were mostly compound heterozygous combinations of two different alleles of missense, nonsense, splice site, and (one) intronic variant. Tables 2 and 3 show the genotypes and their frequencies. The intronic variant c.887-10A $>\mathrm{G}$ (the second most common in the Cordoba cohort) was first described in homozygosity in a Portuguese family, and validated at the mRNA level.[63] it was possibly introduced to LA from Europe.

3. All the individuals (except girl \#147b) showed some degree of residual TPP1 activity when measured in DBS, leukocyte pellet or saliva. Enzyme activities were re-classified in Table 2 as Null Activity (NA) $=0.0$, or Residual Activity (RA) when the values were less than $10 \%$ of the minimal activity in the reference interval (RI).

4. Clinical phenotype: the ages of onset of symptoms ranges between 3-10 years old. Children were often diagnosed after a history of febrile seizures, hyperkinesia, and behavioral disorders with language delay or regression. Refractory seizures were mostly the severe symptom that led to a specialized consultation at our center. Language loss, visual failure and blindness, various movement disorders (mainly ataxia), intellectual regression (dementia), swallowing difficulties, total prostration (palsy), and early death at the third or fourth decade of life marked the evolution of SCAR7 disease. Diagnoses were re-classified as prolonged CLN2 disease with late motor, intellectual and visual failure.[64]

5. TEM features: before the NGS era, TEM was particularly important to include a child in the NCL Program of our Center. Nowadays, TEM is only sporadically indicated, when the diagnosis is highly defiant.
6. Functionality: this item is a description of the current level, and ultimately may use a universally recognized clinical scoring system. Two rating scales comparatively assess the longitudinal scoring data of CLN2 disease: the Hamburg's and the Weill Cornell's scales. In addition, a combination of both scales was used.[9] The rating scales were systematically applied for the study of the longitudinal CLN2 data sets in Europe (DEMCHILD database) and in the USA (WCMC dataset).[9] Figure 5 shows the progression of the longitudinal motor-language scores of Cordoba cohort's 9 individuals with prolonged phenotypes (deficient data were registered from the other 2 individuals). This axis is of particular interest for the study of the evolution of symptoms in children receiving ERT.[9]

7. Other remarks: As the $\mathrm{P}$ subpopulation of children live longer, some remarks can be collected on unusual or individual signs and symptoms.

Some of the individuals included in this work were previously treated in publications of our group. $[8,28]$ The present article shows the peculiarities of more cases allowing a better understanding of the P phenotypes. Two of the individuals are receiving ERT (marked with an asterisk in Table 2). The data collected in the tables are all previous to the ERT application. Genotypes were mostly compound heterozygous combinations of one missense or nonsense DNA variant and one splice site or intronic variant, being the DNA variants E7 c.827A $>$ T, p.Asp276Val and I7 c.887$10 \mathrm{~A}>\mathrm{G}$ the most prevalent. Tables 3 and 4 synthesizes the DNA variant combination of all individuals, including the respective CADD scores.

Three affected male siblings ( $\# 5 \mathrm{a}, \mathrm{b}$, and c in Table 2 ) showed the prolonged course correlating with residual enzyme activity demonstrated in lymphocyte pellet and saliva. The sibs were compound heterozygous for a severe nonsense variant (p.Q66*) and the intronic DNA variant (I7 c.887-10A $>\mathrm{G}$ ) also found in other subjects with a prolonged course in Argentina, Chile $[8,28]$, Portugal[63], Spain[61], and Columbia (NCL Resource - https:// www.ucl.ac.uk/ncl-disease/). Two of the three siblings had a life span of 27 years (one died without a diagnosis), and the other one lived up to 39 years. One Brazilian individual with the same intronic variant in a homozygous state surpassed the $5^{\text {th }}$ decade of life.[18]

Remarkable is also the relatively slow evolution of other 2 sibs (\#147a and b in Table 2) with compound heterozygous missense DNA variants: E8 c.1048C $>$ T, p.Arg350Trp and E13 c.1603G >C, p.Gly535Arg. The elder male sibling had residual enzyme activity, but not the younger girl, as was published elsewhere.[8,28]

Heterogeneous life spans and variations in enzyme activity into the same family could mean that in P phenotypes of the CLN2 disease some still unknown modifier factor (such as genetic, epigenetic or environmental) may affect the phenotype. Further research is needed to investigate this hypothesis. 


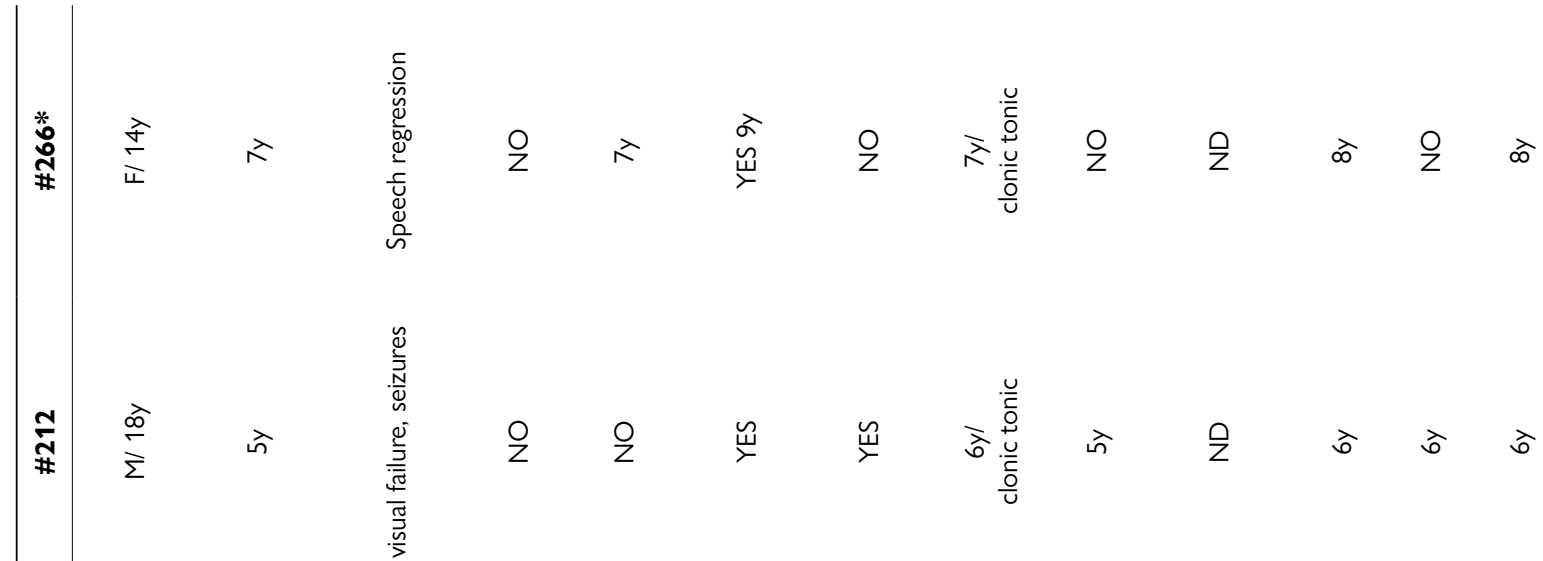

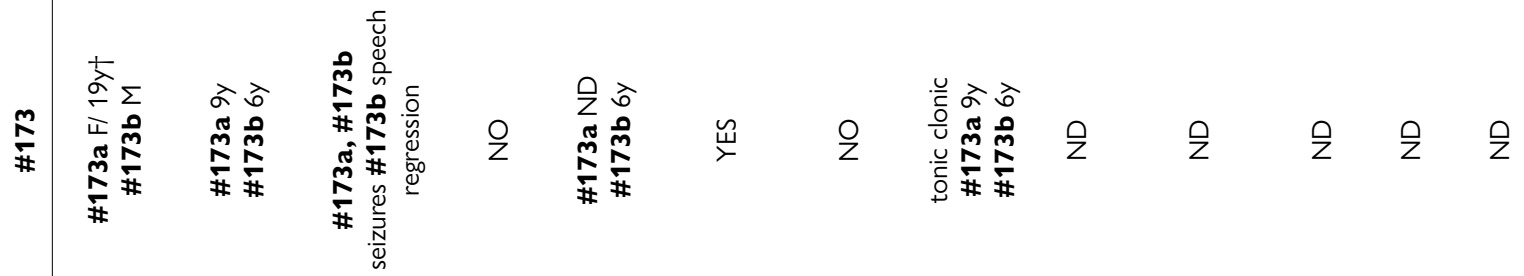

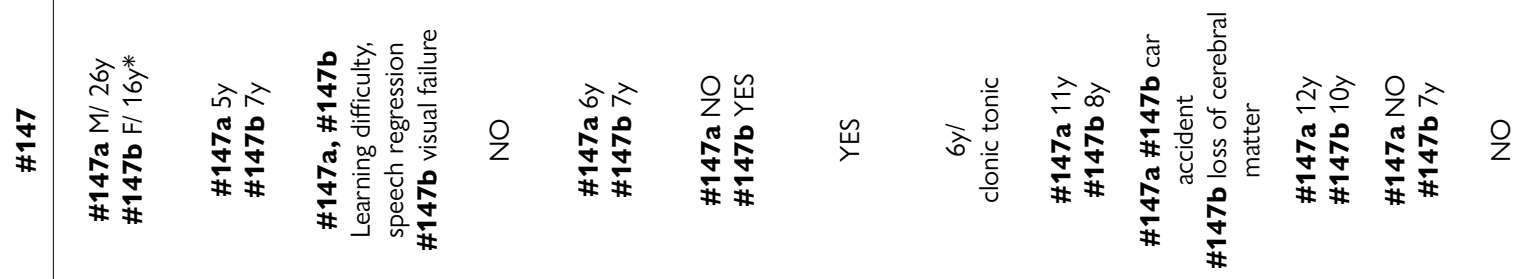

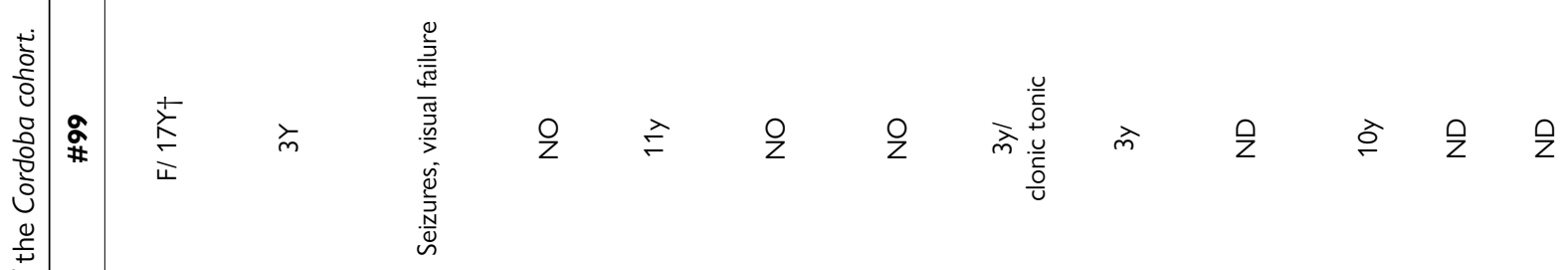

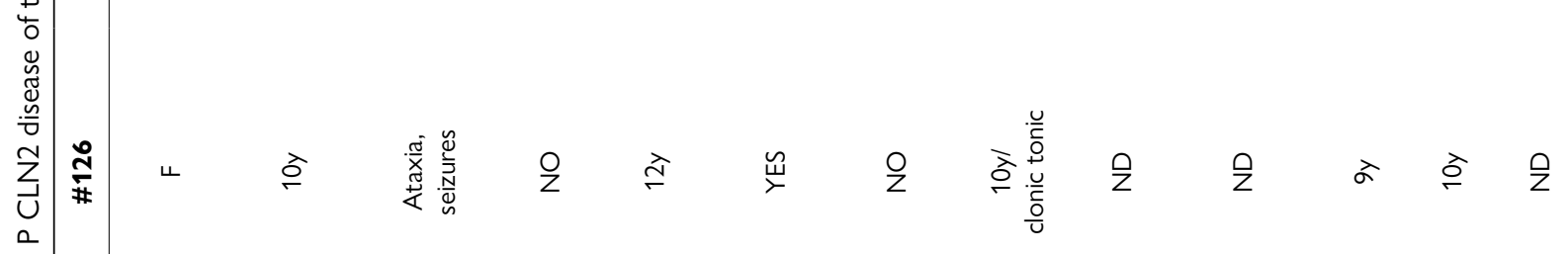

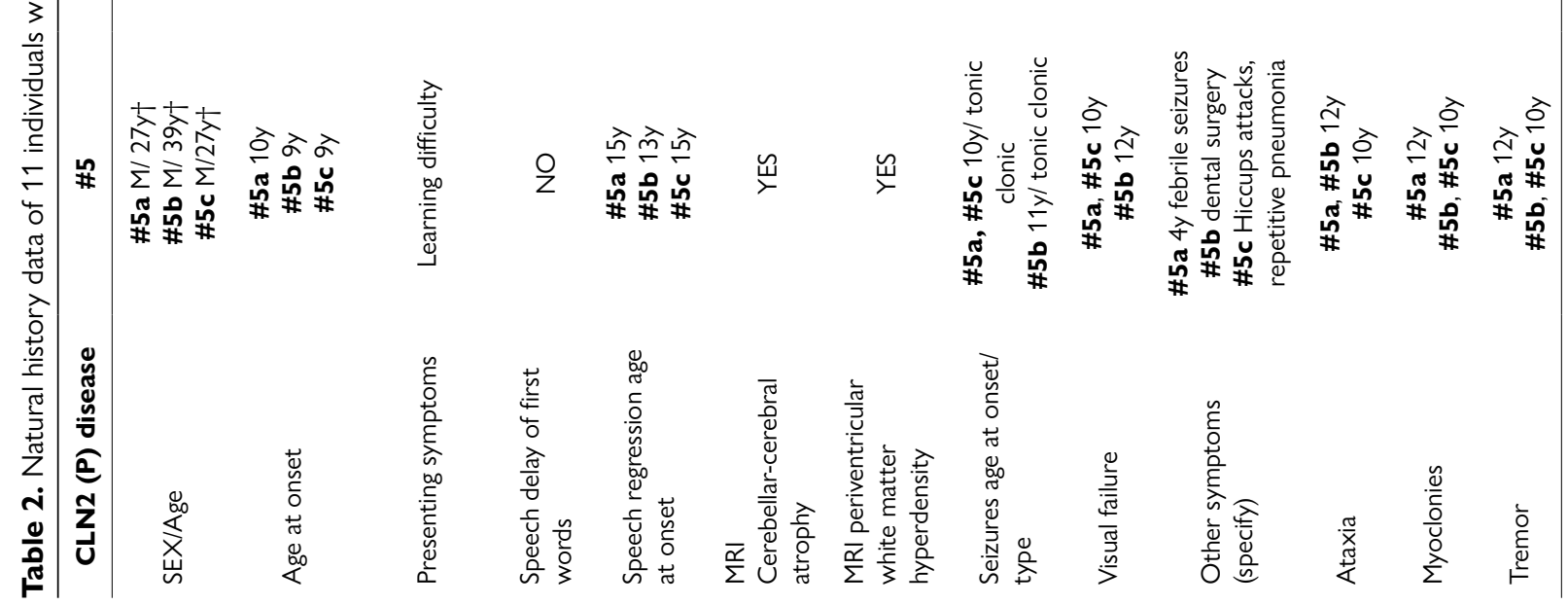




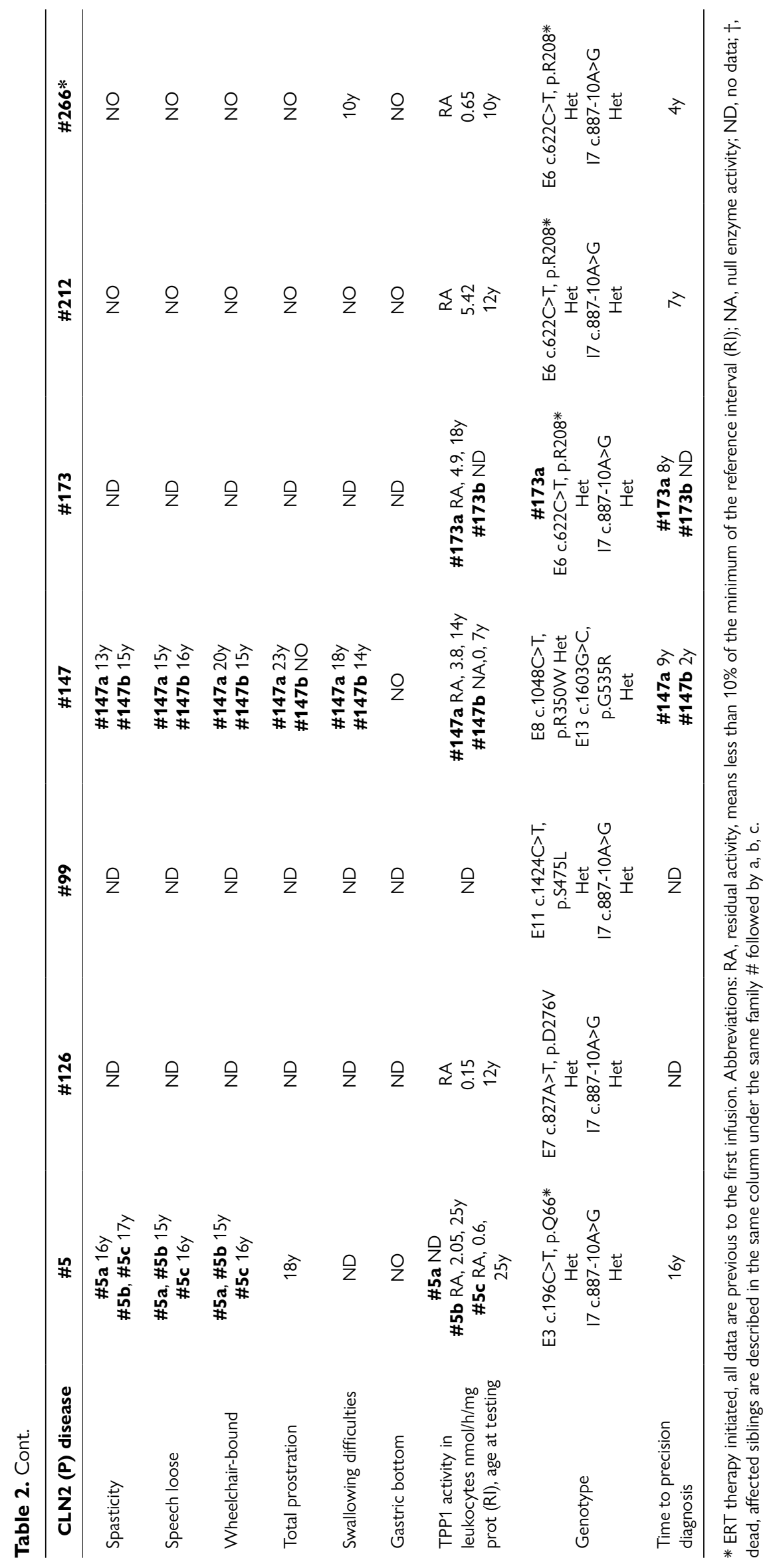



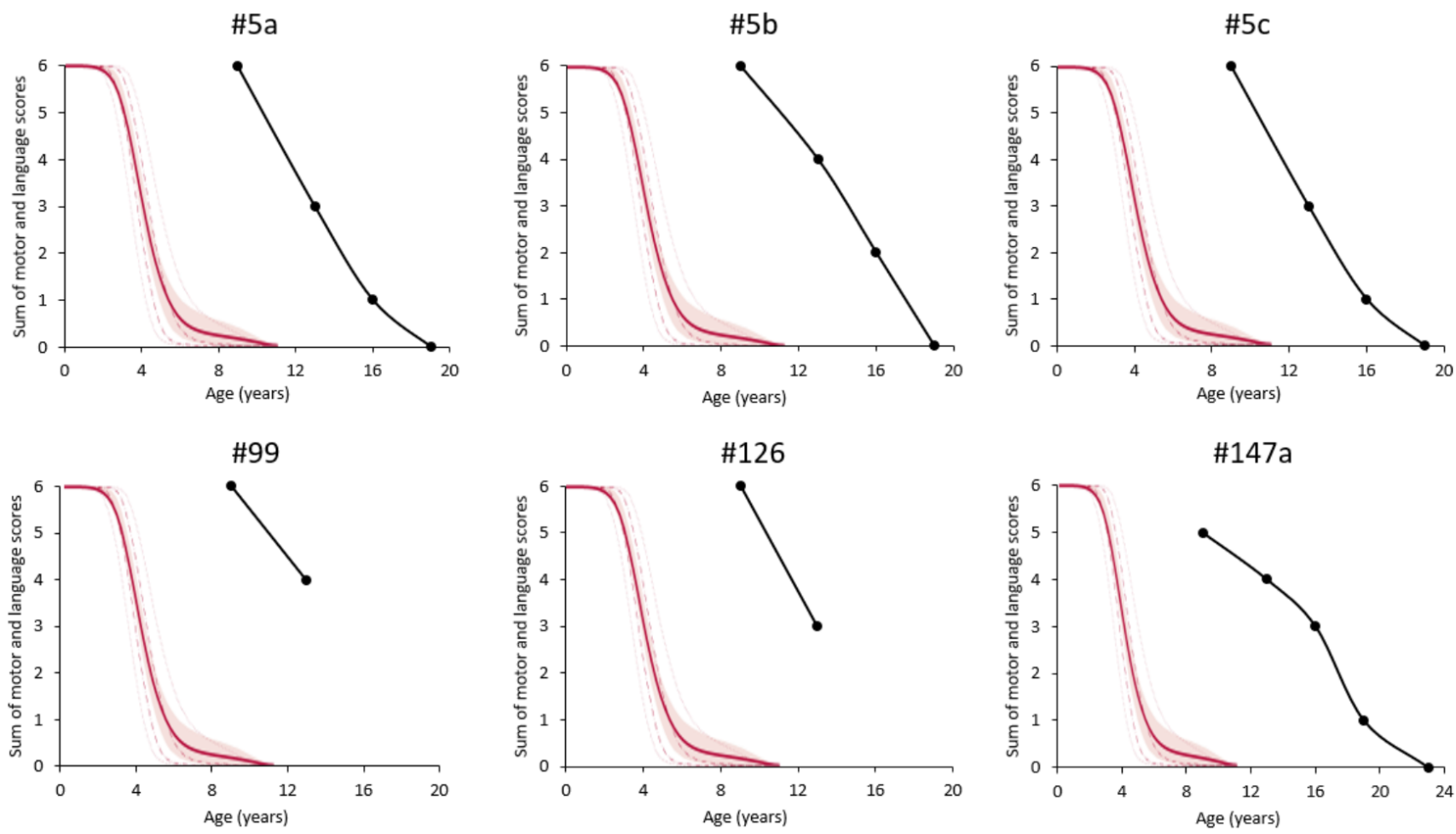

$\# 147 b$

\#212
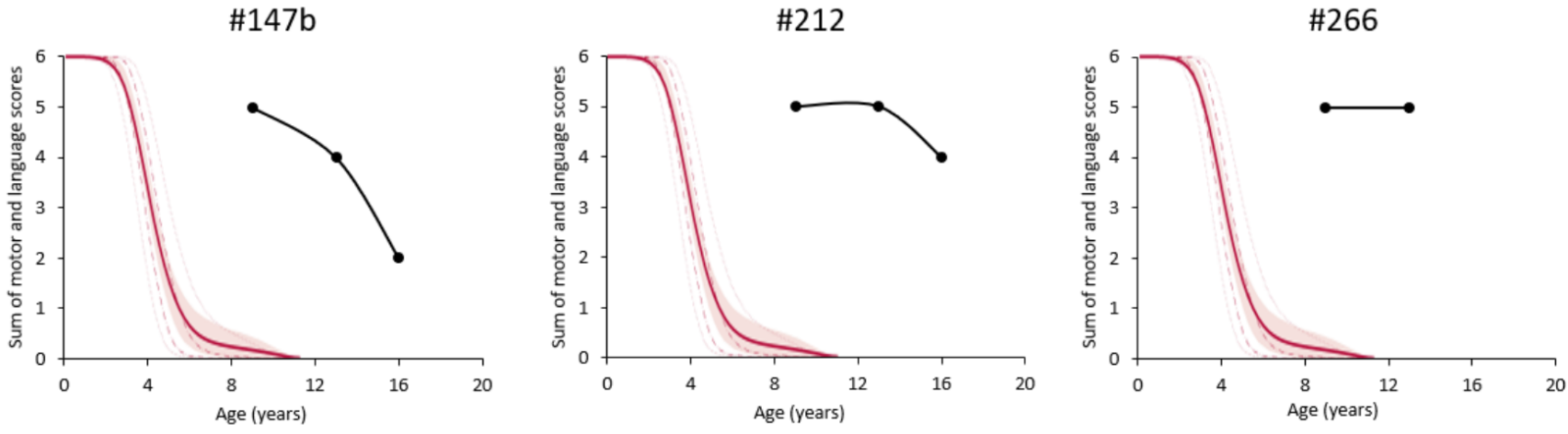

95\% Bootstrap $\mathrm{Cl}$ - Estimated mean

10 perc $\quad-\cdots 25$ perc

75 perc

90 perc

Patient's scores

Figure 5. Progression of motor-language scores of "atypical" CLN2 patients. Graphs showing the evolution of motor-language scores along the natural history of nine CLN2 patients of the Cordoba cohort with "atypical" prolonged phenotype. The respective scores for the natural history of patients with classical CLN2 phenotype[9] is superimposed. It is noteworthy that all the patients had a later onset of symptoms and a slower decline of scores, indicating a slower clinical course.

\section{Atypical congenital CLN8 (OMIM \#600143; *607837)}

CLN8 disease is caused by mutations in the CLN8 gene (OMIM ${ }^{\star} 607837$ ). This pathology can be found with three possible phenotypes: Progressive Epilepsy with Mental Retardation (EPMR, OMIM \#610003), Late Infantile variant (vLI, OMIM \#600143), and congenital variant. EPMR (a.k.a Northern Epilepsy Syndrome) presents as the most protractile form of CLN8 disease. Patients show normal development up to 5-10 years old. The first symptoms may present as frequent refractory generalized tonic-clonic seizures (1-2 per week), which diminish towards adulthood. Psychomotor impairment is continuous until the death of the individual, generally after 40 years of age. Unlike the other forms of CLN8 disease (and most NCLs), patients do not show myoclonus or loss of vision.[1,65] Almost all EPMR patients share the c.70C $>$ G, p.Arg24Gly variant. $[66,67]$ The vLI variant shows a phenotype with symptoms onset at 2-7 years old developing myoclonus, ataxia, speech retardation, developmental regression, visual impairment, loss of cognitive skills, and seizures within 2 years of initiating the symptoms, ending with the loss of ambulation and death within 
Table 3. DNA variants stated in the CLN2 gene of $\mathrm{LI}$ and $\mathrm{P}$ phenotypes of the Cordoba cohort.

\begin{tabular}{|c|c|c|}
\hline \# & Allele 1 & Allele 2 \\
\hline \multicolumn{3}{|c|}{ DNA variants combination of $P$ "atypical" phenotypes } \\
\hline 5 & E3 c. $196 C>T$, p.Gln66* & 17 c. $887-10 A>G$ \\
\hline 126 & E7c.827A>T, p.Asp276Val & 17 c. $887-10 A>G$ \\
\hline 99 & 17 c. $887-10 A>G$ & E11 c.1424C>T, p.Ser475Leu \\
\hline 147 & E8 c.1048C>T, p.Arg350Trp & E13 c.1603G>C, p.Gly535Arg \\
\hline 173 & E6 c.622C>T, p.Arg208* & 17 c. $887-10 A>G$ \\
\hline 212 & E6 c.622C>T, p.Arg208* & 17 c. $887-10 A>G$ \\
\hline 266 & E6 c.622C>T, p.Arg208* & 17 c. $887-10 A>G$ \\
\hline \multicolumn{3}{|c|}{ DNA variants of "classical" LI phenotypes in the Cordoba cohort } \\
\hline 16 & E6 c.622C>T, p.Arg208* & E7 c.827A>T, p.Asp276Val \\
\hline 70 & E7 c.827A>T, p.Asp276Val & E7 c.827A>T, p.Asp276Val \\
\hline 73 & E7 c.827A>T, p.Asp276Val & E7 c.827A>T, p.Asp276Val \\
\hline 82 & E4 c.311T>A, p.Leu104* & E11 c.1358C>T, p.Ala453Val \\
\hline 81 & E7 c.827A>T, p.Asp276Val & E9 c.1107-1108delTG, Gly370Lysfs*32 \\
\hline 117 & E4 c.311T>A, p.Leu104* & E4 c.311T>A, p.Leu104* \\
\hline 123 & E7 c.827A $>$ T, p.Asp276Val & E7 c.827A >T, p.Asp276Val \\
\hline 127 & E6 c.622C>T, p.Arg208* & E7 c.827A>T, p.Asp276Val \\
\hline 134 & E7 c.827A>T, p.Asp276Val & E7 c.827A>T, p.Asp276Val \\
\hline 149 & E11 c.1358C>A, p.Ala453Asp & $12 c .89+5 G>C$ \\
\hline 153 & E6 c.622C>T, p.Arg208* & E6 c.622C>T, p.Arg208* \\
\hline 154 & 15 c.509-1G>C & E7 c.827A>T, p.Asp276Val \\
\hline 162 & E 8 c.1016G>A, p.Arg339Gln & E8 c.1016G>A, p.Arg339Gln \\
\hline 185 & E11 c.1340G>A, p.Arg447His & E11 c. $1424 C>T$, p.Ser475Leu \\
\hline 188 & 11 c. $17+3 G>T$ & E7 c.827A >T, p.Asp276Val \\
\hline $222 a$ & E7 c.827A>T, p.Asp276Val & E7 c.827A >T, p.Asp276Val \\
\hline 305 & 112 c. $1551+1 G>A$ & E5 c.496_496delC, His166Metfs*17 \\
\hline
\end{tabular}

Table 4. Frequency of CLN2 alleles with pathological significance in the Cordoba Cohort.

\begin{tabular}{lccc}
\multicolumn{1}{c}{ Alleles } & dbSNP ID & Allelic frequency & CADD score \\
\hline E7c.827A>T, p.Asp276Val & rs763162812 & 10 & 28.5 \\
I7 c.887-10A>G & rs755445790 & 8 & 5.314 \\
E6 c.622C>T, p.Arg208* & rs119455955 & 6 & 38 \\
E11 c.1358C>T, p.Ala453Val & CM095932 (HGMD) & 4 & 26.5 \\
E3 c.196C>T, p.Gln66* & rs759080581 & 3 & 39 \\
E4 c.311T>A, p.Leu104* & rs202189057 & 3 & 34 \\
I2 c.89+5G>C & rs746085696 & 2 & 25.8 \\
E8 c.1048C>T, p.Arg350Trp & rs1554901784 & 2 & 26 \\
E13 c.1603G>C, p.Gly535Arg & - & 2 & 11.33 \\
I1 c.17+3G>T & - & 1 & 17.74 \\
I5 c.509-1G>C & rs56144125 & 1 & 33 \\
E5 c.496_496delC, His166Metfs*17 & - & 1 & - \\
E11 c.1340G >A, p.Arg447His & rs119455956 & 1 & \\
E11 c.1424C>T, p.Ser475Leu & rs121908202 & 1 & 33 \\
I12 c.1551+1G>A & rs786204553 & 1 & 32 \\
\hline
\end{tabular}


the second decade of life. $[1,61,68]$ Unlike EPMR, DNA variants that correlate with the vLI phenotype are numerous, and have been described worldwide (NCL Resource, https://www.ucl. ac.uk/ncl-disease/). The congenital variant was recently proposed as a novel phenotype.[22] Subjects show psychomotor delay since birth, refractory tonic-clonic seizures since around 3 years old (which usually lead to medical consultation), myoclonus, loss of vision, and a continuous psychomotor decline until a premature death around the beginning of the second decade of life. DNA variants in the congenital phenotype cause deleterious effects on the sequence or expression of $C L N 8$, such as loss of initial codon, small exonic indels, frameshifts, stop-gain variants, and large chromosomal deletions.[22,51,68-72] CLN8 forms the EGRESS complex together with protein CLN6, which participates in the lysosomal biogenesis by transporting soluble lysosomal enzymes to the ERGIC compartment.[73,74] In addition, it is involved in the regulation of key proteins for cellular metabolism.[75,76]

Up to date, one child has been diagnosed with CLN8 disease in the Cordoba cohort. A girl with no known consanguinity presented psychomotor delay and dementia from birth, refractory tonic-clonic seizures from 3 years of age, myoclonus, no visual defects stated, and a continuous psychomotor decline. FP and CL profiles were observed at TEM. At 11 years old, genotyping revealed the pathogenic significant DNA variants $c .1 A>G$, p.?, and c.792C > G, p.Asn264Lys in heterozygous state in the CLN8 gene. She died by the age of 12 years old (Table 5)[22].

In this study, we treat the congenital variant of CLN8 disease as an "atypical" phenotype, in accordance with a previous publication.[22] For a long time only two phenotypes were associated with CLN8 disease (EPMR and vLI), causing the diagnoses to be framed only by them, even if the clinical history differed subtly. Some publications have reported cases with onset of symptoms earlier but they were diagnosed as vLI CLN8. Interestingly, all these "atypical" cases share pathogenic significant variants (such as c.66_66delG, p.Ile23Serfs ${ }^{\star} 5$; c.5442566_590del2613, p.0; c.562_563delCT, p.Leu188Valfs ${ }^{\star 58}$; c. $298 \mathrm{C}>\mathrm{T}$, p.Gln100*; and c.551G $>$ A, p.Trp184*), suggesting a genotype/phenotype correlation for the CLN8 disease.[22,61,68-72]

Table 5. Summary of the natural history features of the CLN8 patient of the Cordoba cohort.

\begin{tabular}{|c|c|}
\hline CLN8 disease & \#110 \\
\hline SEX/Age & F/ 12y† \\
\hline Age at onset & Birth \\
\hline Speech delay of first words & Never completely developed the speech \\
\hline $\begin{array}{l}\text { MRI } \\
\text { Cerebellar-cerebral atrophy }\end{array}$ & Yes \\
\hline MRI periventricular white matter hyperdensity & Not registered \\
\hline Seizures age at onset/type & 3y/tonic clonic \\
\hline Visual failure & Not registered \\
\hline Other symptoms (specify) & Myoclonus, constant tremor, hyperreflexia, and frequent falls \\
\hline \multicolumn{2}{|l|}{ Evolution of symptoms/laboratory (age at onset) } \\
\hline Tremor & $7 y$ \\
\hline Spasticity & Not registered \\
\hline Speech lose & $4 y$ \\
\hline Wheelchair-bound & Not registered \\
\hline Total prostration & $9 y$ \\
\hline Swallowing difficulties & Not registered \\
\hline Gastric bottom & No \\
\hline $\begin{array}{l}\text { Enzyme activity in leukocytes } \\
\mathrm{nmol} / \mathrm{h} / \mathrm{mg} \text { prot (RI), age at testing }\end{array}$ & $\begin{array}{l}\text { PPT1: } 6.9 \text { (6-67), 9y } \\
\text { TPP1: } 17.3 \text { (54-368), 9y }\end{array}$ \\
\hline
\end{tabular}


The congenital CLN8 phenotype is in addition to those of the CLN2, and CLN10 diseases (congenital phenotypes cited in https://www.ucl.ac.uk/ncl-disease/).[5] Interestingly, the deficient enzymes in these disorders (TPP1, and CTSD, respectively) are transported by the EGRESS complex, showing a decrease amount/activity under CLN8 deficiency (and CLN6 deficiency, to less extent).[74] Thus, a concomitant deficiency of these two enzymes, as well as those associated with some other lysosomal pathologies, might be taken for a differential diagnosis of CLN8 and/or CLN6 disorders. Accordingly, the individual we describe in this study has showed a deficient activity (although not separately pathogenic) of both PPT1 and TPP1 enzymes.[22].

\section{Conclusions}

The study strategy through the original algorithm[8] was timeconsuming and required a high degree of expertise. Some of the individuals suffered long diagnostic odysseys before getting a precision diagnosis with the consequent stress of the child and family members. Nowadays, short after the early observation of more than one of the clinical markers of the NCL diseases (speech delay, refractory seizures, intellectual regression, gait and movement disturbance, visual failure), massive genomic analysis is performed with parallel PPT1 and TPP1 enzyme assays and clinical evaluation through electrophysiological and image analyses of eyes and brain. Thereby, it is possible to get a significantly reduced time to arrive at the precision diagnosis. Massive sequencing additionally allowed us to find the pathological definition of atypical phenotypes making possible a detailed comparative description of uncommon phenotypic/ genotypic correlations for CLN1, CLN2, and CLN8 diseases.

The systematic study of the Cordoba cohort of NCL subjects allowed us to recognize the common features with cohorts of other regions, also showing the peculiarities, expectable since the population of LA has mixed ethnic ancestry, such as American Indians, European, Asian, African, etc. The geographical factor seems to be an important one, despite the worldwide distribution of these diseases. The frequency of alleles in the cohort of CLN2 affected individuals is substantially different than in the cohort of the Northern Hemisphere shown by Nickel and collaborators.[9] These authors found two prevalent DNA variants in the relatively homogeneous classical CLN2 disease: one nonsense c.622C>T, p.Arg208*, and one in the splice site c.509-1G>C. As shown in Table 4, the two most frequent DNA variants in the Cordoba cohort are the missense E7c.827A $>$ T, p.Asp276Val, and the intronic I7 c.887-10A $>\mathrm{G}$, the second one being prevalent within the $\mathrm{P}$ phenotype, explaining possibly the relative abundance of this phenotype in our region, and at the same time some residual enzyme activity. Regarding CLN1 and CLN8 disorders, the "atypical" prolonged and congenital phenotypes in the Cordoba cohort, respectively, are of exceptional or sporadic appearance, but its occurrence must be suspected in other individuals of the region. CLN8 with congenital phenotype may be underestimated due to poor neonatal data, such as generalized psychomotor retardation and developmental failure since birth, instead of later motor and intellectual regression.

\section{Acknowledgements}

We want to thank the staff of Hospital de Niños de Cordoba for the space kindly given to the NCL Program, and their collaboration and willingness. To the Centro de Microscopía Electrónica of the Facultad de Ciencias Médicas (Unversidad Nacional de Córdoba) for the provision and work in the analysis of electronic microscopy. To Dr. Romina Kohan, Od. Graciela Alonso, Biol. Gisela Rautenberg, Biol. Claudia Leyes, and all the professionals and students who have worked in the NCL Program since its foundation. This Program was financed along almost 20 years by the Consejo Nacional de Investigaciones Científicas y Técnicas (CONICET), Secretaría de Ciencia y Técnica of the National University of Córdoba, Fondo para la Investigación Científica y Tecnológica (FONCyT), Ministerio de Ciencia y Técnica de la Provincia de Córdoba, National Institute of Health (NIH) and Batten Disease Support and Research Association (BDSRA).

\section{Authors' Contributions}

FP collaborated with the manuscript design, acquisition, analysis, and interpretation of data, manuscript writing, critical revision, and final approval. GG collaborated with the clinical procedures, systematization of clinical data, acquisition, analysis, and interpretation of genomic data, manuscript writing, critical revision, and final approval. ACV collaborated with the acquisition, analysis, and interpretation of data, manuscript writing, critical revision, and final approval. IAC collaborated with the funding, manuscript design, acquisition, analysis and interpretation of data, manuscript writing, critical revision, and final approval. AB collaborated with clinical procedures. JCGV and EF collaborated with the configuration of the MoDAPy platform in our computer system, the bioinformatic analysis of the sequencing data, the critical review of the manuscript, and the final approval. ALDP collaborated with acquisition, analysis, and interpretation of electronic microscopy data, manuscript writing, critical revision, and final approval. $\mathrm{N}$. Guelbert collaborated with clinical procedures, acquisition and interpretation of clinical and genetic data, manuscript writing, critical revision, and final approval. IN collaborated with the funding, manuscript concept and design, acquisition and interpretation of data, manuscript writing, critical revision, and final approval. 


\section{Declaration of Conflicting Interests}

N. Guelbert is a consultant advisor to the pharmaceutical industry in Latin American countries. The other authors declare that they have no conflict of interest.

\section{References}

1. Haltia M. The neuronal ceroid-lipofuscinoses. J Neuropathol Exp Neurol. 2003;62(1):1-13. doi:10.1093/jnen/62.1.1

2. Nelvagal HR, Lange J, Takahashi K, Tarczyluk-Wells MA, Cooper JD. Pathomechanisms in the neuronal ceroid lipofuscinoses. Biochim Biophys Acta - Mol Basis Dis. 2020;1866(9). doi:10.1016/j.bbadis.2019.165570

3. Markham A. Cerliponase Alfa: First Global Approval. Drugs. 2017;77(11):1247-1249. doi:10.1007/s40265-0170771-8

4. Schulz A, Kohlschütter A, Mink JW, Simonati A, Williams RE. NCL diseases - clinical perspectives. Biochim Biophys Acta. 2013;1832(11):1801-1806. doi:10.1016/j. bbadis.2013.04.008

5. Butz ES, Chandrachud U, Mole SE, Cotman SL. Moving towards a new era of genomics in the neuronal ceroid lipofuscinoses. Biochim Biophys Acta - Mol Basis Dis. 2020;1866(9). doi:10.1016/j.bbadis.2019.165571

6. Beck-Wödl S, Harzer K, Sturm M, et al. Homozygous TBC1 domain-containing kinase (TBCK) mutation causes a novel lysosomal storage disease - a new type of neuronal ceroid lipofuscinosis (CLN15)? Acta Neuropathol Commun. 2018;6(1):145. doi:10.1186/s40478-018-0646-6

7. Rider JA, Rider DL. Batten disease: past, present, and future. Am J Med Genet Suppl. 1988;5:21-26. doi:10.1002/ ajmg. 1320310606

8. Nickel M, Simonati A, Jacoby D, et al. Disease characteristics and progression in patients with late-infantile neuronal ceroid lipofuscinosis type 2 (CLN2) disease: an observational cohort study. Lancet Child Adolesc Heal. 2018;2(8):582-590. doi:10.1016/S2352-4642(18)30179-2

9. Kohan R, Pesaola F, Guelbert N, et al. The neuronal ceroid lipofuscinoses program: A translational research experience in Argentina. Biochim Biophys Acta. 2015;1852(10):23002311. doi:10.1016/j.bbadis.2015.05.003

10. Williams RE, Mole SE. New nomenclature and classification scheme for the neuronal ceroid lipofuscinoses. Neurology. 2012;79(2):183-191. doi:10.1212/wnl.0b013e31825f0547

11. Amberger J, Bocchini CA, Scott AF, Hamosh A. McKusick's Online Mendelian Inheritance in Man $\left(\mathrm{OMIM}^{\circledR}\right)$. Nucleic Acids Res. 2009;37(Suppl. 1):D793. doi:10.1093/nar/gkn665
12. Sohar I, Sleat DE, Jadot M, Lobel P. Biochemical characterization of a lysosomal protease deficient in classical late infantile neuronal ceroid lipofuscinosis (LINCL) and development of an enzyme-based assay for diagnosis and exclusion of LINCL in human specimens and animal models. J Neurochem. 1999;73(2):700-711. doi:10.1046/j.1471-4159.1999.0730700.x

13. Lukacs Z, Santavuori P, Keil A, Steinfeld R, Kohlschütter A. Rapid and simple assay for the determination of tripeptidyl peptidase and palmitoyl protein thioesterase activities in dried blood spots. Clin Chem. 2003;49(3):509-511. doi:10.1373/49.3.509

14. Steinfeld R, Reinhardt K, Schreiber K, et al. Cathepsin D deficiency is associated with a human neurodegenerative disorder. Am J Hum Genet. 2006;78(6):988-998. doi: $10.1086 / 504159$

15. Kohan R, Noher de Halac I, Tapia Anzolini V, et al. Palmitoyl Protein Thioesterase1 (PPT1) and Tripeptidyl Peptidase-I (TPP-I) are expressed in the human saliva. A reliable and non-invasive source for the diagnosis of infantile (CLN1) and late infantile (CLN2) neuronal ceroid lipofuscinoses. Clin Biochem. 2005;38(5):492-494. doi:10.1016/j.clinbiochem.2004.12.007

16. Nosková L, Stránecký V, Hartmannová $\mathrm{H}$, et al. Mutations in DNAJC5, encoding cysteine-string protein alpha, cause autosomal-dominant adult-onset neuronal ceroid lipofuscinosis. Am J Hum Genet. 2011;89(2):241-252. doi:10.1016/j.ajhg.2011.07.003

17. Pesaola F, Kohan R, Cismondi IA, et al. Congenital CLN8 disease of Neuronal Ceroid Lipofuscinosis: a novel phenotype. Rev Neurol. 2019;68(4):155-159. doi:10.33588/ rn.6804.2018217

18. Kohan R, Cismondi IA, Oller-Ramirez AM, et al. Therapeutic approaches to the challenge of neuronal ceroid lipofuscinoses. Curr Pharm Biotechnol. 2011;12(6):867-883. doi:10.2174/138920111795542633

19. Kohan R, Cismondi IA, Dodelson de Kremer R, et al. An integrated strategy for the diagnosis of neuronal ceroid lipofuscinosis types 1 (CLN1) and 2 (CLN2) in eleven Latin American patients. Clin Genet. 2009;76(4):372-382. doi:10.1111/j.1399-0004.2009.01214.x

20. Kohan R, Carabelos MN, Xin W, et al. Neuronal ceroid lipofuscinosis type CLN2: a new rationale for the construction of phenotypic subgroups based on a survey of 25 cases in South America. Gene. 2013;516(1):114-121. doi:10.1016/j.gene.2012.12.058

21. Kohan R, Muller VJ, Fietz MJ, Cismondi IA, Oller-Ramirez AM, Noher de Halac I. Gene symbol: TPP1. Disease: Neuronal Ceroid Lipofuscinosis, late infantile. Hum Genet. 2008;123:537-555. doi:10.1007/s00439-008-0503-y 
22. Kohan R, Cannelli N, Aiello C, et al. Gene symbol: CLN5. Disease: Neuronal Ceroid Lipofuscinosis, finnish variant. Hum Genet. 2008;123:537-555. doi:10.1007/s00439-0080503-y

23. Cismondi IA, Kohan R, Ghio A, Oller-Ramirez AM, Noher de Halac I. Gene symbol: CLN6. Disease: Neuronal ceroid lipofuscinosis, late infantile. Hum Genet. 2008;124(3):323324.

24. Cismondi IA, Kohan R, Adams HR, et al. Guidelines for incorporating scientific knowledge and practice on rare diseases into higher education: neuronal ceroid lipofuscinoses as a model disorder. Biochim Biophys Acta. 2015;1852(10 Pt B):2316-2323. doi:10.1016/j. bbadis.2015.06.018

25. Cismondi IA, Cannelli N, Aiello C, et al. Gene symbol: CLN5. Disease: Neuronal Ceroid Lipofuscinosis, Finnish Variant. Hum Genet. 2008;123(5):537-555. doi:10.1007/ s00439-008-0503-y

26. Lourenço CM, Pessoa A, Mendes CC, et al. Revealing the clinical phenotype of atypical neuronal ceroid lipofuscinosis type 2 disease: Insights from the largest cohort in the world. J Paediatr Child Health. 2021; 57:519-525 doi:10.1111/ jpc. 15250

27. Guelbert N, Atanacio N, Denzler I, et al. Position of experts regarding follow-up of patients with Neuronal Ceroid Lipofuscinosis type 2 in Latin America. 2021;(Manuscript under revision).

28. Mole SE, Schulz A, Badoe E, et al. Guidelines on the diagnosis, clinical assessments, treatment and management for CLN2 2 disease patients. 2021;(Manuscript under revision).

29. Yohe S, Thyagarajan B. Review of clinical next-generation sequencing. Arch Pathol Lab Med. 2017;141(11):1544-1557. doi:10.5858/arpa.2016-0501-ra

30. Schulz A, Ajayi T, Specchio N, et al. Study of Intraventricular Cerliponase Alfa for CLN2 Disease. N Engl J Med. 2018;378(20):1898-1907. doi:10.1056/ nejmoa1712649

31. Lewis G, Morrill AM, Conway-Allen SL, Kim B. Review of Cerliponase Alfa: Recombinant Human Enzyme Replacement Therapy for Late-Infantile Neuronal Ceroid Lipofuscinosis Type 2. J Child Neurol. 2020;35(5):348-353. doi:10.1177/0883073819895694

32. Specchio N, Pietrafusa N, Trivisano M. Changing Times for CLN2 Disease: The Era of Enzyme Replacement Therapy. Ther Clin Risk Manag. 2020;16:213-222. doi:10.2147/ TCRM.S241048

33. Fietz MJ, AlSayed M, Burke D, et al. Diagnosis of neuronal ceroid lipofuscinosis type 2 (CLN2 disease): Expert recommendations for early detection and laboratory diagnosis. Mol Genet Metab. 2016;119(1-2):160-167. doi:10.1016/j.ymgme.2016.07.011

34. Mongi-Bragato B, Grondona E, del Valle Sosa L, et al. Pivotal role of NF- $\kappa B$ in cellular senescence of experimental pituitary tumours. J Endocrinol. 2020;245(2):179-191. doi:10.1530/joe-19-0506

35. Richards S, Aziz N, Bale S, et al. Standards and guidelines for the interpretation of sequence variants: A joint consensus recommendation of the American College of Medical Genetics and Genomics and the Association for Molecular Pathology. Genet Med. 2015;17(5):405-424. doi:10.1038/ $\operatorname{gim} .2015 .30$

36. Peña JA, Cardozo JJ, Montiel CM, Molina OM, Boustany RM. Serial MRI findings in the Costa Rican variant of neuronal ceroid-lipofuscinosis. Pediatr Neurol. 2001;25(1):78-80. doi:10.1016/S0887-8994(01)00284-3

37. Taratuto AL, Saccoliti M, Sevlever G, et al. Childhood neuronal ceroid-lipofuscinoses in Argentina. Am J Med Genet. 1995;57(2):144-149. doi:10.1002/ajmg.1320570207

38. Puga AC, Jardim LB, Chimelli L, De Souza CF, Clivati M. Neuronal ceroid lipofuscinoses: a clinical and morphological study of 17 patients from southern Brazil. Arq Neuropsiquiatr. 2000;58(3A):597-606.

39. Gao H, Boustany R-MN, Espinola JA, et al. Mutations in a novel CLN6-encoded transmembrane protein cause variant neuronal ceroid lipofuscinosis in man and mouse. Am J Hum Genet. 2002;70(2):324-335. doi:10.1086/338190

40. Sharp JD, Wheeler RB, Parker KA, Gardiner RM, Williams $\mathrm{RE}$, Mole SE. Spectrum of CLN6 mutations in variant late infantile neuronal ceroid lipofuscinosis. Hum Mutat. 2003;22(1):35-42. doi:10.1002/humu.10227

41. Peña JA, Montiel-Nava C, Delgado W, et al. Characterization of neuronal ceroid lipofuscinosis in Venezuelan children. Rev Neurol. 2004;38(1):42-48.

42. Caraballo R, Sologuestua A, Ruggieri VL, et al. Lipofuscinosis neuronal ceroidea infantil tardía : aspectos clínicos y electroencefalográficos. Rev Neurol. 2005;40(3):135-140. doi:10.33588/rn.4003.2003615

43. Jardim LB, Chimelli L, Clivati M, et al. Ultrastructural analyses in a case series of 34 progressive encephalophaties. In: Noher de Halac I, Dodelson de Kremer R, eds. Neuronal Ceroid Lipofuscinosis (Batten Disease) in Latin America-an Update. Córdoba: Secretaría de Extensión, Universidad Nacional de Córdoba; 2005:117-130.

44. Troncoso L, Erazo R, Troncoso M, Wilting S, Quijada C, Mena F. Neuronal Ceroid Lipofuscinoses: description of 14 cases. In: Noher de Halac I, Dodelson de Kremer R, eds. Neuronal Ceroid Lipofuscinosis (Batten Disease) in Latin America-an Update. Córdoba: Secretaría de Extensión, Universidad Nacional de Córdoba; 2005:151-156. 
45. Ruiz-García M, Hernández-Antunez G, Nieto-Martínez S, Lieberman E, Carrillo-Fraga J. Neuronal Ceroid Lipofuscinoses. Clinical experience in 5 mexican families. In: Noher de Halac I, Dodelson de Kremer R, eds. Neuronal Ceroid Lipofuscinoses (Batten Disease) in Latin América-an Update. Córdoba: Secretaría de Extensión, Universidad Nacional de Córdoba; 2005:157-162.

46. Vasques CO, Valério RMF, Reed UC, Grossman RM, Kok F. Pitfalls in the clinical and electroencephalographic diagnosis of ceroid lipofuscinosis. Arq Neuropsiquiatr. 2005;63(1):93-96. doi:10.1590/s0004-282x2005000100017

47. Pineda-Trujillo N, Cornejo W, Carrizosa J, et al. A CLN5 mutation causing an atypical neuronal ceroid lipofuscinosis of juvenile onset. Neurology. 2005;64(4):740-742. doi:10.1212/01.wnl.0000151974.44980.F1

48. Gama RL, Nakayama M, Távora DGF, Alvim TCDL, Nogueira CD, Portugal D. Neuronal ceroid lipofuscinosis: Clinical and neuroradiological findings. Arq Neuropsiquiatr. 2007;65(2 A):320-326. doi:10.1590/ s0004-282x2007000200025

49. Valadares ER, Pizarro MX, Oliveira LR, et al. Juvenile neuronal ceroid-lipofuscinosis: clinical and molecular investigation in a large family in Brazil. Arq Neuropsiquiatr. 2011;69(1):13-18. doi:10.1590/s0004-282x2011000100004

50. Miranda Contreras L, Delgado Luengo W, Zerpa N, Chacín Hernández J, Chávez CJ, González Ferrer S. Tripeptidil peptidasa 1 en pacientes con ceroidolipofuscinosis neuronal infantil tardía. An Pediatr. 2012;76(3):148-152. doi:10.1016/j.anpedi.2011.09.020

51. Beesley C, Guerreiro RJ, Bras JT, et al. CLN8 disease caused by large genomic deletions. Mol Genet Genomic Med. 2017;5(1):85-91. doi:10.1002/mgg3.263

52. Faber I, Prota JRM, Martinez ARM, Lopes-Cendes I, França MC. A new phenotype associated with homozygous GRN mutations: complicated spastic paraplegia. Eur J Neurol. 2017;24(1):e3-e4. doi:10.1111/ene.13194

53. Beltrán L, Valenzuela GR, Loos M, et al. Late-onset childhood neuronal ceroid lipofuscinosis: Early clinical and electroencephalographic markers. Epilepsy Res. 2018;144:49-52. doi:10.1016/j.eplepsyres.2018.05.005

54. Wibbeler E, Wang R, de los Reyes E, et al. Cerliponase Alfa for the Treatment of Atypical Phenotypes of CLN2 Disease: A Retrospective Case Series. J Child Neurol. 2020. doi:10.1177/0883073820977997

55. Santavuori P, Haltia M, Rapola J. Infantile Type of So-called Neuronal Ceroid-lipofuscinosis. Dev Med Child Neurol. 1974;16(5):644-653. doi:10.1111/j.1469-8749.1974.tb04183.x
56. Lu JY, Verkruyse LA, Hofmann SL. Lipid thioesters derived from acylated proteins accumulate in infantile neuronal ceroid lipofuscinosis: Correction of the defect in lymphoblasts by recombinant palmitoyl-protein thioesterase. Proc Natl Acad Sci U S A. 1996;93(19):1004610050. doi:10.1073/pnas.93.19.10046

57. Van Diggelen OP, Thobois S, Tilikete C, et al. Adult neuronal ceroid lipofuscinosis with palmitoyl-protein thioesterase deficiency: First adult-onset patients of a childhood disease. Ann Neurol. 2001;50(2):269-272. doi:10.1002/ana.1103

58. Bonsignore M, Tessa A, Di Rosa G, et al. Novel CLN1 mutation in two Italian sibs with late infantile neuronal ceroid lipofuscinosis. Eur J Paediatr Neurol. 2006;10(3):154156. doi:10.1016/j.ejpn.2006.04.002

59. Ramadan H, Al-Din AS, Ismail A, et al. Adult neuronal ceroid lipofuscinosis caused by deficiency in palmitoyl protein thioesterase 1. Neurology. 2007;68(5):387-388. doi:10.1212/01.wnl.0000252825.85947.2f

60. Pérez-Poyato MS, Milà Recansens M, Ferrer Abizanda I, et al. Juvenile neuronal ceroid lipofuscinosis: Clinical course and genetic studies in Spanish patients. J Inherit Metab Dis. 2011;34(5):1083-1093. doi:10.1007/s10545-011-9323-7

61. Kousi M, Lehesjoki AE, Mole SE. Update of the mutation spectrum and clinical correlations of over 360 mutations in eight genes that underlie the neuronal ceroid lipofuscinoses. Hum Mutat. 2012;33(1):42-63. doi:10.1002/humu.21624

62. Cárcel-Trullols J, Kovács AD, Pearce DA. Cell biology of the NCL proteins: What they do and don't do. Biochim Biophys Acta. May 2015. doi:10.1016/j.bbadis.2015.04.027

63. Sun Y, Almomani R, Breedveld GJ, et al. Autosomal recessive spinocerebellar ataxia 7 (SCAR7) is caused by variants in TPP1, the gene involved in classic late-infantile neuronal ceroid lipofuscinosis 2 disease (CLN2 disease). Hum Mutat. 2013;34(5):706-713. doi:10.1002/humu.22292

64. Bessa CJP, Teixeira CA, Dias A, et al. CLN2/TPP1 deficiency: the novel mutation IVS7-10A $>$ G causes intron retention and is associated with a mild disease phenotype. Mol Genet Metab. 2008;93(1):66-73. doi:10.1016/j.ymgme.2007.08.124

65. Herva R, Tyynelä J, Hirvasniemi A, Syrjäkallio-Ylitalo M, Haltia M. Northern epilepsy: a novel form of neuronal ceroid-lipofuscinosis. Brain Pathol. 2000;10(2):215-222. doi:10.1111/j.1750-3639.2000.tb00255.x

66. Ranta S, Zhang Y, Ross B, et al. The neuronal ceroid lipofuscinoses in human EPMR and mnd mutant mice are associated with mutations in CLN8. Nat Genet. 1999;23(2):233-236. doi:10.1038/13868 
67. Siintola E, Lehesjoki AE, Mole SE. Molecular genetics of the NCLs - status and perspectives. Biochim Biophys Acta. 2006;1762(10):857-864. doi:10.1016/j.bbadis.2006.05.006

68. Reinhardt K, Grapp M, Schlachter K, Brück W, Gärtner J, Steinfeld R. Novel CLN8 mutations confirm the clinical and ethnic diversity of late infantile neuronal ceroid lipofuscinosis. Clin Genet. 2010;77(1):79-85. doi:10.1111/ j.1399-0004.2009.01285.x

69. Cannelli N, Cassandrini D, Bertini ES, et al. Novel mutations in CLN8 in Italian variant late infantile neuronal ceroid lipofuscinosis: Another genetic hit in the Mediterranean. Neurogenetics. 2006;7(2):111-117. doi:10.1007/s10048005-0024-y

70. Allen NM, O’hIci B, Anderson GW, Nestor T, Lynch SA, King MD. Variant late-infantile neuronal ceroid lipofuscinosis due to a novel heterozygous CLN8 mutation and de novo 8p23.3 deletion. Clin Genet. 2012;81(6):602604. doi:10.1111/j.1399-0004.2011.01777.x

71. Gao Z, Xie H, Jiang Q, Wu N, Chen X, Chen Q. Identification of two novel null variants in CLN8 by targeted next-generation sequencing: first report of a Chinese patient with neuronal ceroid lipofuscinosis due to CLN8 variants. BMC Med Genet. 2018;19(1):21. doi:10.1186/s12881-018-0535-7
72. Alkhars FZ, Bo Ali AY, Almohanna MA, Almajhad NA. Neuronal ceroid lipofuscinoses type 8: Expanding genotype/ phenotype diversity-first report from Saudi Arabia. Neurosciences (Riyadh). 2020;25(1):65-69. doi:10.17712/ nsj.2020.1.20190103

73. Bajaj L, Sharma J, Di Ronza A, et al. A CLN6-CLN8 complex recruits lysosomal enzymes at the ER for Golgi transfer. $J$ Clin Invest. 2020;130(8):4118-4132. doi:10.1172/jci130955

74. Di Ronza A, Bajaj L, Sharma J, et al. CLN8 is an endoplasmic reticulum cargo receptor that regulates lysosome biogenesis. Nat Cell Biol. 2018;20(12):1370-1377. doi:10.1038/s41556018-0228-7

75. Adhikari B, De Silva B, Molina JA, Allen A, Peck SH, Lee SY. Neuronal ceroid lipofuscinosis related ER membrane protein CLN8 regulates PP2A activity and ceramide levels. Biochim Biophys Acta - Mol Basis Dis. 2019;1865(2):322328. doi:10.1016/j.bbadis.2018.11.011

76. Passantino R, Cascio C, Deidda I, et al. Identifying protein partners of CLN8, An ER-resident protein involved in neuronal ceroid lipofuscinosis. Biochim Biophys Acta. 2013;1833(3):529-540. doi:10.1016/j.bbamcr.2012.10.030 